\title{
Fecal Lactoferrin As A Diagnostic and Prognostic Marker in Egyptian IBD Patients Mohamed M. Makhlouf ${ }^{1}$, Wael A. Yousry ${ }^{1}$, Shereen Abou Bakr Saleh ${ }^{1}$, Ahmed Mohamed Naguib ${ }^{1}$, Christina Alphonse Anwar*2
}

${ }^{1}$ Internal Medicine Department, Hepatology and Gastroenterology Unit, Faculty of Medicine, Ain Shams University, Egypt. ${ }^{2}$ Internal Medicine Department, Hepatology and Gastroenterology Unit, Faculty of Medicine, Ain Shams University and AFCM.

*Corresponding author: Christina Alphonse Anwar, Mobile: (+20)01201276220, Email: Christina.alfons@yahoo.com

\begin{abstract}
Background: Inflammatory bowel diseases (IBD) are organic chronic inflammation of the gastrointestinal tract characterized by variable disease activity with repeated periods of remission and exacerbation. Irritable bowel syndrome (IBS) is prevalent in up to fifth of population; diarrhea type has the broadest differential diagnosis. To distinguish inflammatory versus functional disorder fecal biomarkers as fecal lactoferrin (FL), being non-invasive acute phase proteins produced by inflamed mucosa, can help to avoid invasive procedures. Objective: The aim of this study was to assess sensitivity and specificity of fecal lactoferrin as a non-invasive biomarker in Egyptian patients with IBD and to detect its role in assessment of disease severity.

Patients and methods: This comparative case control study was held through one year duration. Patients were recruited from Internal Medicine and Hepatology Department at a University Hospital. 50 subjects were classified into 3 groups: Group I included 30 patients with inflammatory bowel disease, Group II included 10 patients with irritable bowel syndrome, Group III included 10 healthy subjects as control group.

Results: fecal lactoferrin assay (FLA) levels were highest in patients with IBD in comparison with IBS patients and healthy group. Moreover FLA levels also correlated significantly with disease severity in patients with IBD as higher levels of FLA were found in patients with severe ulcerative colitis (UC) or Crohn`s disease.

Conclusion: Fecal lactoferrin can be used to differentiate IBD from IBS with $96.7 \%$ sensitivity and $100 \%$ specificity at cutoff value of $37 \mathrm{ug} / \mathrm{ml}$ while at cutoff value $7.2 \mathrm{ug} / \mathrm{ml}$ FLA has $100 \%$ sensitivity and specificity in differentiating IBD patients from healthy subjects in Egyptian population. Yet it can't differentiate ulcerative colitis versus Crohn's disease. Keywords: Inflammatory bowel diseases, Irritable bowel syndrome, Lactoferrin.
\end{abstract}

\section{INTRODUCTION}

Inflammatory bowel disease (IBD) is a chronic inflammatory condition of the gastrointestinal tract comprising two forms; Crohn's disease (CD) and ulcerative colitis (UC). It is a lifelong relapsing and remitting disease in random unpredictable patterns ${ }^{(\mathbf{1})}$, caused through molecular mimicry in genetically predisposed patients to unknown initiator resulting in macroscopic inflammation of the GIT with recurrent episodes of relapse and remission ${ }^{(2)}$.

IBS is a functional disorder, which may result from alterations in the gut microbiome, maldigestion of carbohydrates, psychologically mediated effects, and dysregulation of immunity ${ }^{(3-4)}$. Patients with IBD and irritable bowel syndrome (IBS) share many clinical symptoms, including abdominal pain, diarrhea and generalized malaise ${ }^{(5)}$.

IBS should be diagnosed based on ROME IV criteria $^{(6)}$, in the absence of alarm features with no need for extensive investigations other than routine serologic screening for celiac disease in patients with diarrheapredominant IBS or mixed IBS and colonic mucosal biopsies for microscopic colitis when performing colonoscopy in patients with diarrhea-predominant IBS (7). Yet, a lot of doctors consider IBS as a "diagnosis of exclusion" ordering multiple diagnostic tests to rule out various organic diseases before confidently diagnosing IBS $^{(8)}$.
Data suggests that IBD is of low prevalence among patients with IBS symptoms and no alarm features ${ }^{(\mathbf{9 , 1 0})}$, yet there is significant symptom overlap between both conditions ${ }^{(\mathbf{1 1}-13)}$ with some IBD patients with symptoms meeting symptom-based criteria for the diagnosis of IBS ${ }^{(\mathbf{1 3})}$.

Colonoscopy and biopsy are corner stone in IBD diagnosis, yet it is invasive, expensive, embarrassing and time consuming with severe complications in some conditions ${ }^{(\mathbf{1 4})}$, therefore, non-invasive, simple and accurate tests were needed to differentiate IBD from IBS patients and to assess severity of IBD. Erythrocyte sedimentation rate (ESR), C-reactive protein (CRP), and leukocytes are serum biomarkers influenced by multiple systemic host responses which make them nonspecific for intestinal inflammation ${ }^{(\mathbf{1 4})}$. Fecal biomarkers are increasingly used to assess activity in IBD due to direct correlations with intestinal inflammation $^{(\mathbf{1})}$. Neutrophil - granular proteins as lactoferrin, lysozymes, calprotectin are of fecal markers of intestinal inflammation ${ }^{(15)}$.

Lactoferrin (FL) is an $80 \mathrm{kDa}$ glycoprotein with iron-binding capacity. Being a part of innate immunity, lactoferrin is present in various secretory fluids, including milk and nasal secretions ${ }^{(\mathbf{1 6})}$ with antimicrobial activity but it is not affected by age variation, or extraintestinal causes of inflammation ${ }^{(17,18)}$. 
During intestinal inflammation, neutrophils are translocated in the mucosa, neutrophil apoptosis and degradation increases lactoferrin concentration in feces ${ }^{(19,20)}$. FL remains stable in feces for up to 7 days at room temperature is easily assessed by enzyme linked immune sorbent assay (ELISA) ${ }^{(21)}$. Therefore, FL was suggested to identify IBD activity (more accurate than to distinguish between IBD and other diseases as it is elevated in stool with any cause of increase of neutrophils in intestinal mucosa) ${ }^{(\mathbf{2 1})}$, to predict relapse and to evaluate responses to treatment such antitumor necrosis factor (anti-TNF- $\alpha$ ) treatment ${ }^{(22,23)}$.

The aim of this study was to assess the fecal lactoferrin levels in Egyptian patients with IBD and patients with IBS and to compare them with normal subjects to detect its sensitivity and specificity as a noninvasive biomarker in identification of such patients. Our study also included measurement of FLA levels at different stages of inflammatory bowel disease activity to detect its role in assessment of disease severity.

\section{PATIENTS AND METHODS}

This comparative case control study was held through one year duration. Patients were recruited from Internal Medicine and Hepatology Department at Ain Shams University Hospital.

After excluding patients with any malignancies, autoimmune disease or other causes of malabsorption and tuberculosis using clinical and histopathological examination, 30 patients with confirmed diagnosis of IBD, who were diagnosed using colonoscopy and histopathological examination, were recruited as first case group (group I). The second case group (group II) included 10 patients of those with diagnosis of IBS after excluding organic causes using ultrasound, laboratory data and colonoscopy. While the control group (group III) included 10 apparently healthy subjects with no acute or chronic illness and were not on medications.

All study members were further assessed regarding history of extraintestinal manifestations of IBD (uveitis, arthritis, skin lesions, etc...), general wellbeing, changes in bowel habits and its duration and frequency, presence or absence of blood and mucous, analysis of any abdominal pain, then vital data was recorded, body mass index (BMI) was calculated and abdomen was locally examined especially for tenderness or masses.

Laboratory data of blood counts (CBC), liver and coagulation profile, kidney functions as well as inflammatory markers (ESR, CRP) with stool analysis and culture and fecal lactoferrin were collected from all participants.

Fecal lactoferrin assay was done; samples taken from first bowel movement of the day using quantitative enzyme-linked immunosorbent assay (ELISA) using Lactoferrin human ELISA kit (HLF2) lot \# GWB1EA11D by Genway Biotech Inc., San Diego, USA. This was done according to manufacturer recommendations attached with kits.

Patients included were 23 males (46\%) and 27 females (54\%) with age range from 18-48 years.

Severity index was assessed for IBD patients using Crohn's disease activity Index (CDAI) for clinical assessment in $\mathrm{CD}$ and Truelove and Witts Severity Index for patients with UC. For CDAI ; a score $<150$ means disease quiescence, 150 to 219 corresponds to mild activity, 220 to 450 for moderately activity; and > 450 means severe disease. Accordingly, 5 patients had inactive disease, 11 patients with mild activity ( 9 with UC, 2 with Crohn's), 6 patients with moderate activity (4 with UC, 2 with Crohn`s) and 8 with severe activity (7 with UC, 1 with Crohn's) ${ }^{(24)}$.

\section{Ethical consent:}

An approval of the study was obtained from Academic and Ethical Committee, Ain Shams University. Every patient signed an informed written consent for acceptance of sharing in the study. This work has been carried out in accordance with The Code of Ethics of the World Medical Association (Declaration of Helsinki) for studies involving humans.

\section{Statistical analysis}

Data were analyzed using SPSS 15.0 version, Quantitative data were presented as mean $\underline{t}$ standard deviation (SD), and range. One way analysis of variance (ANOVA) followed by Tukey's test was used to compare means. $\mathrm{P}$ value was considered significant at 0.05 .

\section{RESULTS}

On comparing the 3 groups of the study, there were no significant differences regarding age, sex, BMI, liver enzymes, bilirubin, hemoglobin or kidney functions. Yet, there were statistically significant differences between 3 groups regarding white blood cells, platelets, total proteins, serum albumin, stool red blood cells (RBCs) and pus cells as well as ESR, CRP (Table 1). 
Table (1): Comparison between 3 study groups regarding CBC, stool analysis, plasma proteins and inflammatory markers

\begin{tabular}{|c|c|c|c|c|c|c|c|c|c|c|c|}
\hline & \multicolumn{8}{|c|}{ Groups } & \multicolumn{2}{|c|}{ ANOVA } \\
\hline & & \multicolumn{3}{|c|}{$\begin{array}{c}\text { Inflammatory bowel } \\
\text { Disease } \mathbf{N}=\mathbf{3 0} \\
\end{array}$} & \multicolumn{2}{|c|}{$\begin{array}{c}\text { Irritable bowel } \\
\text { syndrome } \mathbf{N}=10\end{array}$} & \multicolumn{3}{|c|}{$\begin{array}{c}\text { Controls } \\
\mathrm{N}=10\end{array}$} & \multirow{2}{*}{$\begin{array}{c}\mathbf{F} \\
6.817\end{array}$} & \multirow{2}{*}{$\begin{array}{c}\text { P-value } \\
0.003^{*}\end{array}$} \\
\hline $\begin{array}{l}\text { Albumin } \\
(\mathrm{g} / \mathrm{dl})\end{array}$ & $\begin{array}{l}\text { Mean } \\
\pm \text { SD }\end{array}$ & 3.567 & \pm & 0.659 & 4.210 & $\pm \quad 0.685$ & 4.270 & \pm & 0.472 & & \\
\hline $\begin{array}{c}\text { Total } \\
\text { proteins } \\
\text { (g/dl) } \\
\end{array}$ & $\begin{array}{l}\text { Mean } \\
\pm \text { SD }\end{array}$ & 6.083 & \pm & 0.671 & 6.300 & $\pm \quad 0.519$ & 6.940 & \pm & 0.422 & 7.571 & $0.001 *$ \\
\hline $\begin{array}{c}\text { Stool } \\
\text { WBCs } \\
(\mathrm{mcL}) \\
\end{array}$ & $\begin{array}{c}\text { Mean } \\
\pm \text { SD } \\
\end{array}$ & 31.133 & \pm & 6.844 & 2.200 & $\pm \quad 0.393$ & 1.000 & \pm & 0.108 & 6.230 & $0.004 *$ \\
\hline $\begin{array}{l}\text { Stool } \\
\text { RBCs } \\
\text { (mcL) } \\
\end{array}$ & $\begin{array}{c}\text { Mean } \\
\pm \text { SD } \\
\end{array}$ & 38.100 & \pm & 5.845 & 1.000 & 0.491 & 1.00 & \pm & 0.333 & 6.364 & $0.004 *$ \\
\hline $\begin{array}{c}\text { PLT } \\
(\mathbf{m c L})\end{array}$ & $\begin{array}{l}\text { Mean } \\
\pm \text { SD } \\
\end{array}$ & 367.000 & \pm & 15.223 & 300.000 & \pm 8.318 & 299.700 & \pm & 7.318 & 2.914 & 0.064 \\
\hline $\begin{array}{c}\text { WBC } \\
(\mathrm{mcL})\end{array}$ & $\begin{array}{l}\text { Mean } \\
\pm \text { SD }\end{array}$ & 11.887 & \pm & 2.725 & 7.830 & \pm 1.063 & 7.520 & \pm & 1.762 & 9.843 & $<0.001 *$ \\
\hline $\begin{array}{c}\text { ESR } \\
(\mathrm{mm} / \mathrm{hr})\end{array}$ & $\begin{array}{l}\text { Mean } \\
\pm \text { SD }\end{array}$ & 23.133 & \pm & .278 & 13.200 & $\pm \quad 2.936$ & 11.500 & \pm & 2.598 & 10.170 & $<0.001 *$ \\
\hline $\begin{array}{c}\text { CRP } \\
(\mathrm{mg} / \mathrm{L})\end{array}$ & $\begin{array}{l}\text { Mean } \\
\pm \text { SD }\end{array}$ & 34.600 & \pm & 2.549 & 7.800 & $\pm \quad 1.898$ & 7.200 & \pm & 1.530 & 8.138 & $0.001 *$ \\
\hline
\end{tabular}

Lower levels of total proteins, serum albumin were found in patients with IBD in comparison with IBS patients and control group. Stool RBCs and pus cells, ESR, CRP and total WBC were significantly higher in IBD (typically UC) patients when compared to IBS and control groups, yet there was no statistically significant difference between IBS patients and controls in any of these parameters (Table 2).

Table (2): Comparison of every 2 studied groups regarding significantly different variables using post-hoc test

\begin{tabular}{|l|c|c|c|c|c|c|}
\hline \multicolumn{1}{|c|}{ Items } & $\begin{array}{c}\text { UC and } \\
\text { Crohn`s }\end{array}$ & UC and IBS & $\begin{array}{c}\text { UC and } \\
\text { Control }\end{array}$ & $\begin{array}{c}\text { Crohn`s and } \\
\text { IBS }\end{array}$ & $\begin{array}{c}\text { Crohn`s and } \\
\text { Control }\end{array}$ & $\begin{array}{c}\text { IBS and } \\
\text { Control }\end{array}$ \\
\hline Albumin (g/dl) & 0.977 & 0.058 & $0.032^{*}$ & 0.154 & 0.109 & 0.997 \\
\hline $\begin{array}{l}\text { T. proteins (g/dl) } \\
\text { Stool WBCs } \\
\text { (mcL) }\end{array}$ & 0.605 & 0.898 & $0.005^{*}$ & 0.398 & $0.005^{*}$ & 0.094 \\
\hline $\begin{array}{l}\text { Stool RBCs } \\
\text { (mcL) }\end{array}$ & 0.861 & $0.034^{*}$ & $0.026^{*}$ & 0.612 & 0.565 & 1.000 \\
\hline WBC (mcL) & 0.831 & $0.026^{*}$ & $0.026^{*}$ & 0.603 & 0.603 & 1.000 \\
\hline ESR (mm/hr) & 0.439 & $0.013^{*}$ & $0.007^{*}$ & 0.073 & $0.049^{*}$ & 0.997 \\
\hline CRP (mg/L) & 0.653 & $0.028^{*}$ & $0.006^{*}$ & $0.009^{*}$ & $0.003^{*}$ & 0.967 \\
\hline
\end{tabular}

Regarding fecal lactoferrin, there was a significantly higher mean in IBD patients than other two groups, moreover it was also significantly higher in IBD group on comparing every two groups separately while there was no significant difference between IBS patients and control group. Fecal lactoferrin showed no significant differences between UC and CD patients (Table 3 ). 
Table (3): Comparison of FLA in different study groups

\begin{tabular}{|c|c|c|c|c|c|c|c|c|}
\hline \multirow{2}{*}{\multicolumn{2}{|c|}{ Groups }} & \multicolumn{5}{|c|}{ Lactoferrin } & \multicolumn{2}{|c|}{ ANOVA } \\
\hline & & \multicolumn{2}{|c|}{ Range } & \multirow{2}{*}{$\begin{array}{c}\text { Mean } \\
1158.433\end{array}$} & \multirow{2}{*}{$\begin{array}{l} \pm \\
\pm\end{array}$} & \multirow{2}{*}{$\begin{array}{c}\text { SD } \\
1332.909 \\
\end{array}$} & \multirow{4}{*}{$\begin{array}{c}\mathbf{F} \\
7.276\end{array}$} & P-value \\
\hline \multicolumn{2}{|c|}{ Inflammatory bowel Disease } & 110 & 5403 & & & & & \multirow{3}{*}{$0.002 *$} \\
\hline \multicolumn{2}{|c|}{ Irritable bowel syndrome } & 0.4 & 37 & 8.400 & \pm & 11.842 & & \\
\hline \multicolumn{2}{|c|}{ Controls } & 0.4 & 7.2 & 2.460 & \pm & 2.278 & & \\
\hline \multicolumn{9}{|c|}{ TUKEY'S Test } \\
\hline UC and Crohn`s & UC and IBS & \multicolumn{2}{|c|}{\begin{tabular}{l|l} 
UC and & C \\
Control & \\
\end{tabular}} & $\begin{array}{l}\text { hn`s and } \\
\text { IBS }\end{array}$ & \multicolumn{2}{|c|}{$\begin{array}{c}\text { Crohn`s and } \\
\text { Control }\end{array}$} & \multicolumn{2}{|c|}{$\begin{array}{l}\text { IBS and } \\
\text { Control }\end{array}$} \\
\hline 0.721 & $0.045^{*}$ & \multicolumn{2}{|c|}{$0.043^{*}$} & $.037 *$ & \multicolumn{2}{|c|}{$0.036^{*}$} & \multicolumn{2}{|c|}{1.000} \\
\hline
\end{tabular}

FLA showed significant direct relation with disease severity that it was significantly higher in severe activity than all other grades of severity (Table 4).

Table (4): Comparison of fecal lactoferrin levels in patients with inflammatory bowel disease at different stages of activity

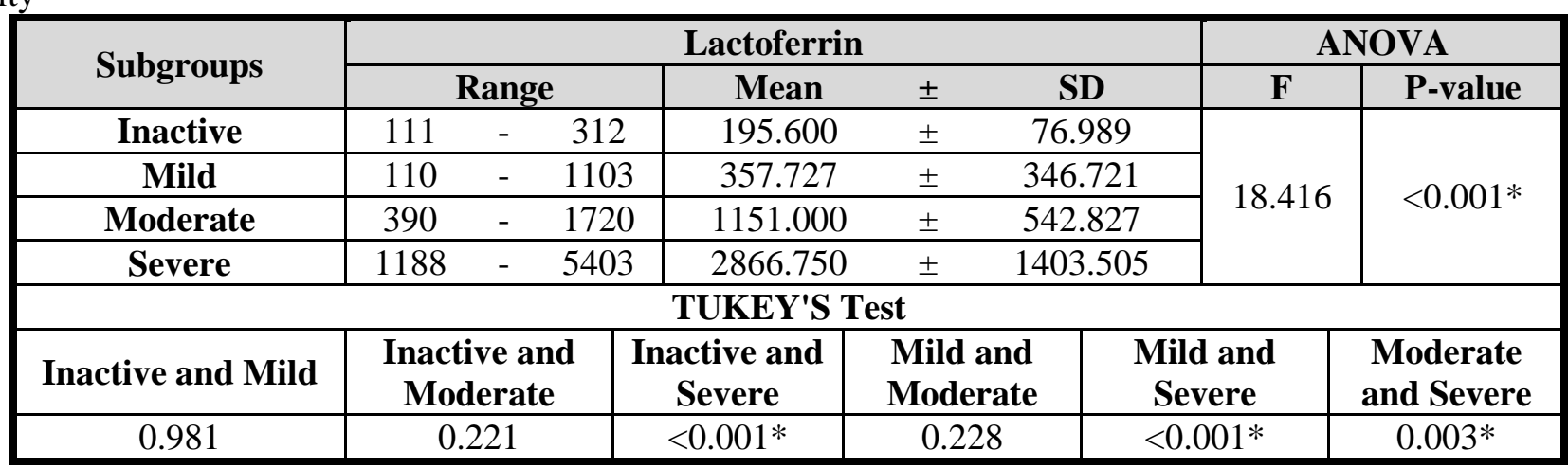

Fecal lactoferrin showed $96.7 \%$ and $100 \%$ sensitivity in discriminating IBD patients from IBS patients and healthy people respectively, with $100 \%$ specificity for both (Table 5 and Figs. 1 and 2).

Table (5): Diagnostic value of FLA levels in discriminating patients with IBD patients from IBS patients and healthy people

\begin{tabular}{|c|c|c|c|c|c|c|}
\hline $\begin{array}{c}\text { Differentiation } \\
\text { between }\end{array}$ & \multicolumn{6}{|c|}{ ROC curve } \\
\hline IBD versus IBS & Cutoff & Sensitivity & Specificity & $\begin{array}{c}\text { Positive } \\
\text { predictive } \\
\text { value }\end{array}$ & $\begin{array}{c}\text { Negative } \\
\text { predictive } \\
\text { value }\end{array}$ & Accuracy \\
\cline { 2 - 7 } & $>37 *$ & 96.7 & 100.0 & 100.0 & 90.9 & $99.7 \%$ \\
\hline $\begin{array}{c}\text { IBD versus } \\
\text { healthy people }\end{array}$ & $>7.2 *$ & 100.0 & 100.0 & 100.0 & 100.0 & $100 \%$ \\
\hline
\end{tabular}




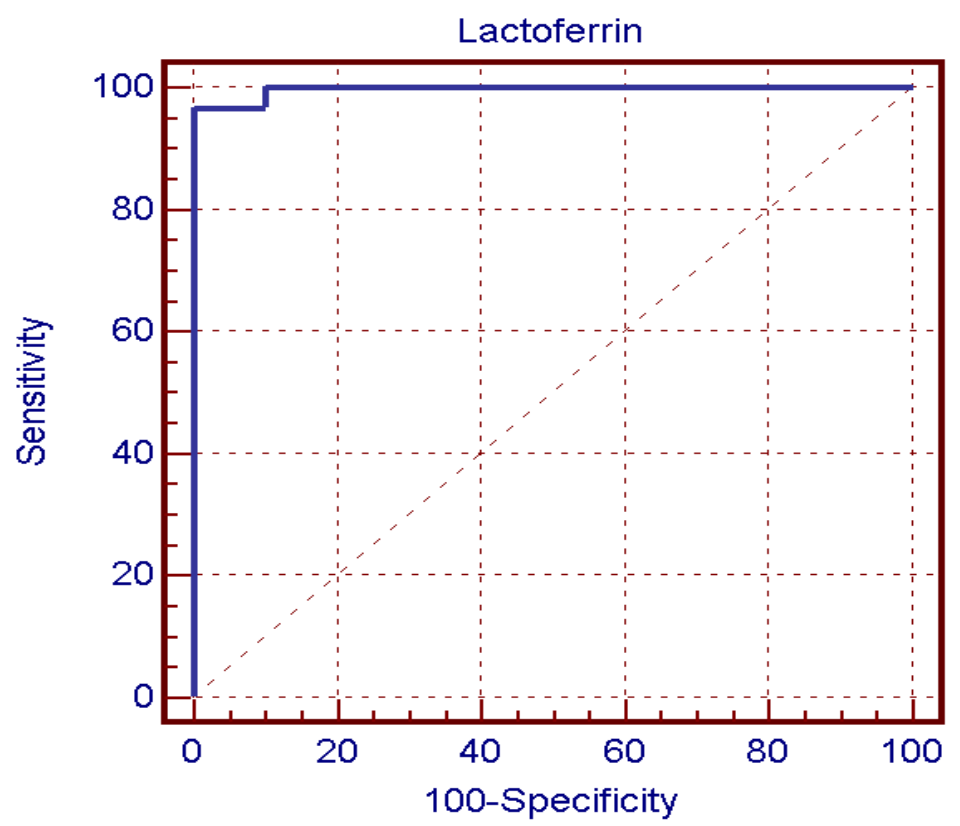

Figure (1): Receiver operator curve analysis was done to estimate the diagnostic value of FLA levels in discriminating patients with IBD from IBS patients.

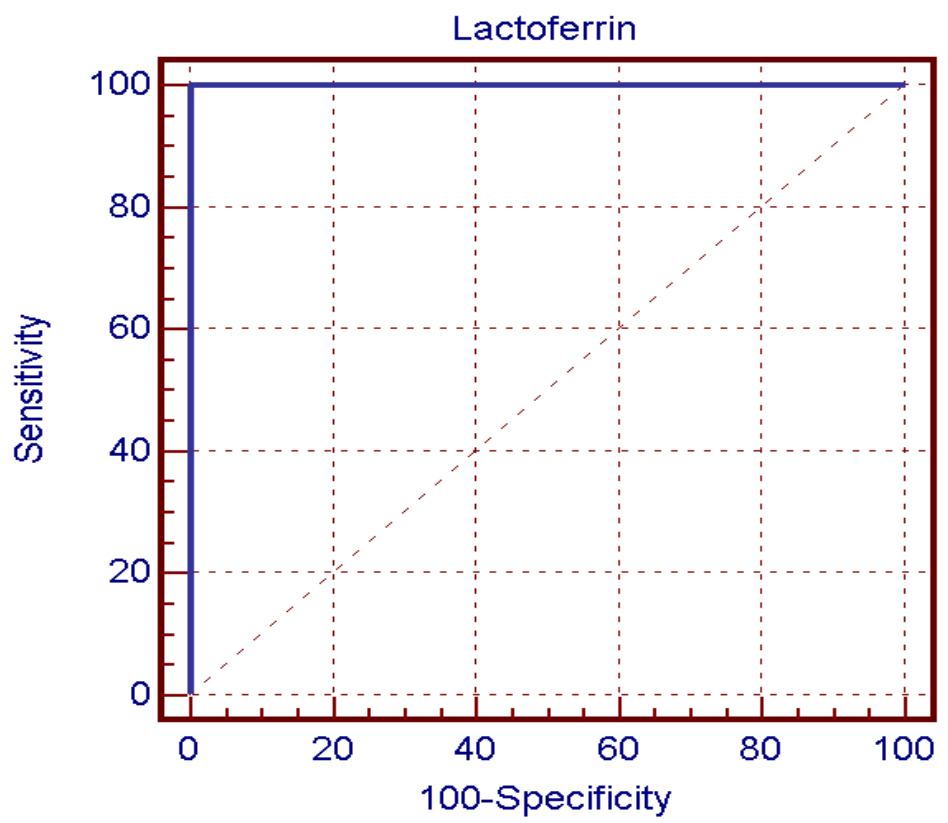

Figure (2): Receiver operator curve analysis was done to estimate the diagnostic value of FLA levels in discriminating patients with IBD from healthy subjects.

\section{DISCUSSION}

Altered bowel habits and abdominal pain are common symptoms in many diseases of gastrointestinal tract and other systems. It is challenging to differentiate patients with IBD from those with IBS, especially diarrhea type, as both conditions, although different in pathophysiology and prognosis present with similar symptom complex ${ }^{(25)}$. Inflamed intestinal mucosa in IBD is associated with fecal markers that either leak from, or are generated due to inflammation. Accordingly these markers can be used to differentiate inflammatory conditions from functional disorders.
Moreover they can be used to assess disease activity, treatment effect and prediction of relapse ${ }^{(15)}$. Elevated FLA has been used as a marker of active IBD and for monitoring patients for response to treatment ${ }^{(26)}$.

The aim of this study was to assess the fecal lactoferrin levels in Egyptian patients with IBD and patients with IBS and to compare them with normal subjects to detect its sensitivity and specificity as a noninvasive biomarker in identification of such patients. Our study also included measurement of FLA levels at different stages of inflammatory bowel disease activity to detect its role in assessment of disease 
severity. This study was carried on 50 subjects classified into 3 groups: Group I was 30 patients with inflammatory bowel disease, Group II was 10 patients with irritable bowel syndrome, Group III was 10 healthy subjects served as control group.

This study showed significant elevation of fecal lactoferrin levels in IBD patients than in IBS ones and healthy persons. These findings agreed with Walker $\boldsymbol{e t}$ $\boldsymbol{a l} \mathbf{l}^{(27)}$, who reported higher levels of FLA levels in patients with IBD than in control group. This finding may be due to increase of neutrophils in intestinal mucosa of patients with IBD with higher production of lactoferrin in patient's stools than healthy groups. These results also agree with Sidhu et $\boldsymbol{a l} .{ }^{(28)}$, who found that levels of FLA varied significantly in patients with IBD when compared to those with IBS or healthy subjects (p-value <0.001).

This study did not detect a significant difference in FLA levels between patients with UC and those with $\mathrm{CD}$, in agreement with Walker $\boldsymbol{e t}$ al. ${ }^{(27)}$, who found the same. But that was opposed by a meta-analysis which concluded that lactoferrin have greater ability to evaluate $\mathrm{UC}$ than $\mathrm{CD}^{(\mathbf{1 4})}$.

Similarly, No significant difference was found between FLA levels in IBS patients and control group. This agrees with study done by Zhou et $\boldsymbol{a l} .{ }^{(29)}$, which showed similar values of FLA in patients with IBS and healthy subjects.

FLA levels varied significantly in patients with IBD according to disease severity. Higher levels were found in patients with severe IBD than patients with inactive IBD. This agrees with Sidhu et al. ${ }^{(28)}$, whose study showed FLA levels varied significantly with disease activity in UC and Crohn`s disease with pvalues $<0.001,0.002$ respectively. On the other hand no significant difference in FLA levels was found between patients with inactive IBD and those with mild activity. This agrees with the reported results of a meta-analysis showing that FLA is a cheap, stable, easy and helpful marker for IBD screening with strong sensitivity and specificity for IBD activity assessment ${ }^{(14)}$.

FLA levels had good sensitivity and specificity in distinguishing patients with IBD from those with IBS and healthy controls, according to a comparison of receiver operating characteristic curves. Comparing FLA levels in patients with IBD and IBS patients, FLA was found to be highly sensitive and highly specific in differentiating patients with IBD from those with IBS with cutoff value $>37 \mathrm{ug} / \mathrm{ml}$. This agrees with Walker et $\boldsymbol{a l} .{ }^{(27)}$, who showed high sensitivity $83.5 \%$ and high specificity $96.6 \%$ for fecal lactoferrin in distinguishing patients with IBD from those with IBS. These results also agrees with other studies done by Schröder $\boldsymbol{e t}$ $\boldsymbol{a l .}{ }^{(\mathbf{3 0})}$, whose results showed high sensitivity (82\%) and specificity (100\%) for FLA levels in discriminating patients with IBD from those with IBS. A 7 studies meta-analysis for fecal lactoferrin showed a pooled sensitivity of 0.78 (95\% confidence interval: $0.75-0.82$ ) and a specificity of 0.94 (95\% confidence interval:
0.91-0.96) in differentiating IBD from IBS. However, this meta-analysis utilized studies with varying test cutoffs and mixed both adults and children populations ${ }^{(29)}$, This is in the contrary to another study, which showed that high levels of fecal lactoferrin were more predictive of IBS than IBD ${ }^{(7)}$.

Comparing FLA levels in patients with IBD and healthy controls, FLA was found to be highly sensitive and highly specific in differentiating patients with IBD from healthy subjects with cutoff value $>7.2 \mathrm{ug} / \mathrm{ml}$. This agrees with Sidhu et al ${ }^{(28)}$, who found high sensitivity and specificity for FLA in differentiation of patients with IBD from healthy controls (sensitivity $71 \%$, specificity $100 \%$ ).

\section{Limitation:}

Small sample size with discrepancy in sizes of the compared groups, no follow up to assess its response to treatment and that we did not compare lactoferrin with other fecal biomarkers regarding accuracy.

\section{CONCLUSION}

Fecal lactoferrin can be used to differentiate IBD from IBS with $96.7 \%$ sensitivity and $100 \%$ specificity at cutoff value of $37 \mathrm{ug} / \mathrm{ml}$ while at cutoff value 7.2 $\mathrm{ug} / \mathrm{ml}$ FLA has $100 \%$ sensitivity and specificity in differentiating IBD patients from healthy subjects in Egyptian population. Yet it can't differentiate ulcerative colitis versus Crohn's disease.

Financial support and sponsorship: Nil. Conflict of interest: Nil.

\section{REFERENCES}

1. Liu F, Lee S, Riordan S et al. (2020): Global studies of using fecal biomarkers in predicting relapse in inflammatory bowel disease. doi: 10.3389/ fmed. 2020.580803

2. Kim D, Cheon J (2017): Pathogenesis of inflammatory bowel disease and recent advances in biologic therapies. Immune Netw., 17:25-40.

3. Thabane M, Kottachchi D, Marshall J (2007): Systematic review and meta-analysis: the incidence and prognosis of postinfectious irritable bowel syndrome. Aliment Pharmacol Ther., 26:535-544.

4. Maxwell P, Rink E, Kumar D et al. (2002): Antibiotics increase functional abdominal symptoms. Am J Gastroenterol., 97:104-108.

5. van de Vijver E, Schreuder A, Cnossen W et al. (2012): The North Netherlands Pediatric IBD Consortium Safely ruling out inflammatory bowel disease in children and teenagers without referral for endoscopy. Arch Dis Child, 97: 1014-1018.

6. Ford A, Moayyedi P, Lacy B et al. (2014): American College of Gastroenterology monograph on the management of irritable bowel syndrome and chronic idiopathic constipation. Am J Gastroenterol., 109(1): 2 26.

7. Menees S, Powell C, Kurlander J et al. (2015): A Metaanalysis of the utility of C-reactive protein, erythrocyte sedimentation rate, fecal calprotectin, and fecal lactoferrin 
to exclude inflammatory bowel disease in adults with IBS. American Journal of Gastroenterology, 110 (3): 444-454.

8. Spiegel B, Farid M, Esrailian E et al. (2010): Is irritable bowel syndrome a diagnosis of exclusion? A survey of primary care providers, gastroenterologists, and IBS experts. Am J Gastroenterol., 105:848-858.

9. Cash B, Schoenfeld P, Chey W (2002): The utility of diagnostic tests in irritable bowel syndrome patients: a systematic review. Am J Gastroenterol., 97:2812-2819.

10. Chey W, Nojkov B, Rubenstein J et al. (2010): The yield of colonoscopy in patients with non-constipated irritable bowel syndrome: results from a prospective, controlled US trial. Am J Gastroenterol., 105:859-865.

11.Porter C, Cash B, Pimentel M et al. (2012): Risk of inflammatory bowel disease following a diagnosis of irritable bowel syndrome. BMC Gastroenterol., 12:55-58.

12.Pimentel $M$, Chang $M$, Chow E et al. (2000): Identification of a prodromal period in Crohn's disease but not ulcerative colitis. Am J Gastroenterol., 95:34583462 .

13. Halpin S, Ford A (2012): Prevalence of symptoms meeting criteria for irritable bowel syndrome in inflammatory bowel disease: systematic review and metaanalysis. Am J Gastroenterol., 107:1474-1482.

14.Jiang D, Sun M, Cao M et al. (2020): Fecal lactoferrin for assessment of inflammatory bowel disease activity: A systematic review and meta-analysis. Journal of Clinical Gastroenterology, 54(6): 545-553.

15. Legrand D (2016): Overview of lactoferrin as a natural immune modulator. J Pediatr., 173: 10-15.

16. Brock J (2012): Lactoferrin--50 years on. Biochem Cell Biol., 90:245-251.

17.Poullis A, Foster R, Northfield T et al. (2002): Faecal markers in the assessment of activity in inflammatory bowel disease. Aliment Pharmacol Ther., 16:675-681.

18. Gisbert J, McNicholl A, Gomollon F (2009): Questions and answers on the role of fecal lactoferrin as a biological marker in inflammatory bowel disease. Inflamm Bowel Dis., 15:1746-1754.

19. Kopylov U, Rosenfeld G, Bressler B et al. (2014): Clinical utility of fecal biomarkers for the diagnosis and management of inflammatory bowel disease. Inflamm Bowel Dis., 20:742-756.

20.Guerrant R, Araujo V, Soares E et al. (1992): Measurement of fecal lactoferrin as a marker of fecal leukocytes. J Clin Microbiol., 30:1238-1242.
21. Joishy M, Davies I, Ahmed M et al. (2009): Fecal calprotectin and lactoferrin as noninvasive markers of pediatric inflammatory bowel disease. J Pediatr Gastroenterol Nutr., 48:48-54

22. Buderus S, Boone J, Lyerly D et al. (2004): Fecal lactoferrin: a new parameter to monitor infliximab therapy. Dig Dis Sci., 49:1036-1039.

23.Sipponen T, Savilahti E, Karkkainen P et al. (2008): Fecal calprotectin, lactoferrin, and endoscopic disease activity in monitoring anti-TNF-alpha therapy for Crohn's disease. Inflamm Bowel Dis., 14:1392-1398.

24. Lichtenstein G, Rutgeerts P, Sandborn W et al. (2012): A pooled analysis of infections, malignancy, and mortality in infliximab- and immunomodulator-treated adult patients with inflammatory bowel disease. Am J Gastroenterol., 107:1051-1063.

25. Bernstein C, Fried M, Krabshuis J et al. (2010): World Gastroenterology Organization Practice Guidelines for the diagnosis and management of IBD in 2010. Inflammatory Bowel Diseases, 16:112-124.

26.Sipponen T, Kärkkäinen P, Savilahti E et al. (2008): Correlation of faecal calprotectin and lactoferrin with an endoscopic score for Crohn's disease and histological findings. Alimentary Pharmacology and Therapeutics, 28: 1221-1229.

27. Walker T, Land M, Kartashov A et al. (2007): Fecal lactoferrin is a sensitive and specific marker of disease activity in children and young adults with inflammatory bowel disease. Journal of Pediatric Gastroenterology and Nutrition, 44: 414-422

28. Sidhu R, Wilson P, Wright A et al. (2010): Faecal lactoferrin-a novel test to differentiate between the irritable and inflamed bowel? Aliment Pharmacol Ther., 31(12):1365-1370.

29.Zhou X, Xu W, Tang X et al. (2014): Fecal lactoferrin in discriminating inflammatory bowel disease from irritable bowel syndrome: a diagnostic meta-analysis. BMC Gastroenterol., 14: 121-125.

30.Schröder O, Naumann M, Shastri Y et al. (2007): Prospective evaluation of fecal neutrophil-derived proteins in identifying intestinal inflammation: combination of parameters does not improve diagnostic accuracy of calprotectin. Alimentary Pharmacology and Therapeutics, 26: 1035-1042. 